\title{
IDEOLOGÍA Y MOVIMIENTOS CULTURALES: UNA NOTA SOBRE SU INFLUENCIA EN LA ACTIVIDAD LINGÜÍSTICA
}

\author{
IDEOLOGY AND CULTURAL MOVEMENTS: A NOTE ON ITS INFLUENCE IN \\ LINGUISTIC RESEARCH
}

Antonio FÁBREGAS

IS-Universitetet i Tromsø

\begin{abstract}
RESUMEN:
Una vista de pájaro sobre los movimientos culturales en Latinoamérica y su recepción en España nos muestra que se fue pasando progresivamente de cierta preconcepción de que las naciones hispanohablantes de América debían necesariamente aceptar la supremacía cultural de España, fundada en su precedencia histórica, hasta un planteamiento más policéntrico en el que, poco a poco, se iba aceptando la autonomía de las naciones americanas, hasta culminar en el concepto de panhispanismo, que es estándar en nuestros días, al menos sobre el papel. El objetivo de este trabajo es hacer una cala en esta evolución cultural y mostrar cómo se refleja en dos aspectos del estudio de la lengua: el diccionario y la gramática. Más en particular, exploraremos cómo la actividad lingüística de la Real Academia Española y la Asociación de Academias durante el siglo XX y los comienzos del XXI siguió un desarrollo que replica estos cambios culturales, pivotando sobre todo en los conceptos de unidad, diversidad y panhispanismo, que han sido centrales en la historia cultural reciente de Latinoamérica.
\end{abstract}

PALABRAS CLAVE: voseo, indigenismo, unidad, diversidad, panhispanismo.

\section{ABSTRACT:}

An overview over Latinamerican cultural movements and the way in which they were received in Spain shows that there was a process whereby progressively there has been a movement from a view where Spanish-speaking countries in America had to accept the cultural supremacy of Spain towards a more polycentric situation where little by little the autonomy of American Nations was accepted; this culminates currently in the concept of Panhispanism, which is the standard today, at least on paper. The goal of this article is to address this cultural process as it is instantiated in two aspects of grammatical research: dictionaries and grammars. We will explore how the linguistic activity of the Real Academia Española and the Asociación de Academias during the 20th and 21st centuries follows a path that replicates these cultural changes, always gravitating around the notions of unity, diversity and Panhispanism, which have been central in the recent history of Latinamerica.

KEY WORDS: voseo, indigenism, unity, diversity, Panhispanism. 


\section{Polos EN CONTACTO: CULTURA Y LENGUA}

Tal vez no se espera que los movimientos culturales tengan influencia en ciertas ciencias, como la lingüística. El objetivo de este trabajo es mostrar que esta preconcepción no es exacta, y que la evolución de los movimientos culturales latinoamericanos que redefinieron durante el siglo XX la relación de América con España tienen un reflejo directo en la forma en que se tratan ciertos aspectos de la gramática y el léxico del español.

Esto no resulta sorprendente cuando se considera que, dentro de la lingüística, hay aspectos que interactúan de forma muy estrecha con la cultura general y los cambios políticos o sociales, porque se refieren a la forma en que distintos organismos de poder estandarizan usos lingüísticos y fomentan su difusión a través de las instituciones educativas y los medios de comunicación. En este trabajo mostraremos cómo los cambios ideológicos y culturales pueden ayudarnos a entender por qué se producen modificaciones en ciertas formas de concebir la lengua en un sentido amplio. La parte lingüística de nuestro análisis toma la actividad normativa y filológica desempeñada por la Real Academia Española -y, con el correr de los tiempos, la Asociación de Academias de la Lengua Española- durante el siglo pasado y este. Este artículo, pues, se centra exclusivamente en un ámbito hispánico.

Dividiremos el estudio en tres partes que responden a tres momentos culturales diferentes en la relación de América con España. En la primera parte nos concentraremos en la noción de mestizaje que se difundió tanto en América como en España durante los años veinte y veremos cómo tienen su réplica en la actividad de la RAE durante el mismo periodo. La segunda parte del estudio presenta la creación del concepto cultural de panhispanismo y cómo España no integra esta noción en su modo de actuar; esto se refleja también en la actividad lingüística de la RAE. La tercera parte se dedica al establecimiento de una cooperación cultural más estable entre España y Latinoamérica y cómo esto hace que el panhispanismo se esté integrando también, como concepto relevante para la lingüística en España.

Debemos hacer notar que este trabajo no trata de juzgar la validez moral de las ideas que se discuten. No creemos que sea nuestra tarea la de hacer de jueces, y sin duda no estamos cualificados para ello. En tanto que esas ideas son producto de un ambiente cultural determinado, es posible que no fueran muchas las opciones alternativas. Nuestra intención es la de actuar como notarios más que como jueces, y limitarnos a presentar una serie de hechos y relacionarlos con ciertos aspectos ideológicos que, creemos, se asocian a ellos.

\section{MESTIZAJE: «DIVERSIDAD» COMO ANTÓNIMO DE «UNIDAD»}

Esta historia podría comenzar mucho antes, pero tal vez un momento apropiado para dejarla empezar es en México en 1925. En ese año, José Vasconcelos, que había sido rector de la Universidad Nacional y hasta el año anterior Secretario de Educación Pública, publica La raza cósmica. Este libro es simbólico no solo por provenir de un 
intelectual activo políticamente y con cierto poder -lo cual permite pensar que sus ideas no podían estar lejos de la ideología de las instituciones oficiales de México- sino también por la forma en que define una noción de mestizaje que tendría efectos en la historia de las ideas (cfr. Tierney, 2007; Hill, 2009). Asimismo, el hecho de que sea un intelectual mexicano nos permitirá enlazar con la siguiente parte de este trabajo, en el que veremos cómo estas ideas se tratan de implementar en el siglo XX en un concepto panamericano conocido aún hoy como panhispanismo.

¿Qué entiende Vasconcelos por mestizaje? La raza cósmica, que es el concepto fundamental en este ensayo, es una única raza en la que se fusionan, sin distinguirse unas de otras, todas las razas de la tierra. El valor de América es precisamente el de haber nacido cultural y antropológicamente del mestizaje entre las cuatro razas de la tierra: la blanca, la negra, la roja y la amarilla. A través de esta raza única y unificada es posible eliminar los conflictos que habían aquejado a la humanidad en etapas anteriores de la historia. La ecuación es sencilla: si los conflictos nacen de las diferencias entre los seres humanos, eliminadas estas diferencias, desaparecen automáticamente dichos conflictos. Lo que falla en la ecuación es la igualdad que se establece entre raza y carácter. Recuérdese que La raza cósmica está llena de generalizaciones que igualan las razas a ciertas formas de comportamiento. Así, por ejemplo, se afirma de la raza amarilla (o malaya) que «nadie les gana en cautela y habilidad, y aun, si es necesario, en perfidia» (p. 37).

Es bastante claro que en un sistema como este, los indígenas americanos (la raza roja) no pueden mantener una identidad autónoma. La diversidad que surge de la convivencia de las cuatro razas en América es sacrificada, en aras de la paz y la tranquilidad, a favor de una quinta raza que se sobreponga a estas idiosincrasias y se alce como abanderada de una nueva era. No se trata solo de que el objetivo que se quiere alcanzar sea simplificador; el punto de partida es, de manera interesante, igualmente simplificador, ya que la raza roja es dada como una única entidad atómica, sin establecer diferencia alguna entre los numerosos pueblos amerindios y sus identidades distintivas. Este planteamiento elimina la diversidad, sin distinciones, para alcanzar la paz. Su teoría y su práctica están más próximos al indianismo que constituyó una de las corrientes del romanticismo brasileño -donde se trataba de reflejar la dualidad de la sociedad fusionando motivos indígenas con técnicas europeas- que a lo que podría considerarse una reclamación de la identidad individual de los pueblos amerindios.

Es importante destacar, aunque sea bien conocido, que este planteamiento ideológico se refleja en la corriente política e ideológica oficial del gobierno mexicano $\mathrm{y}$, en buena medida, puede considerarse la columna vertebral de los cambios culturales que, por oposición a las tendencias europeizantes anteriores, se implantaron en el México nacido tras la Revolución. No es casual que Vasconcelos ocupara cargos en el gobierno y se presentara él mismo a la presidencia unos años después de la publicación de esta obra. Tampoco es casual que sus contemporáneos manifestaran, en distintos ámbitos, estas mismas preocupaciones y favorecieran la fusión de distintas corrientes en un mismo resultado homogéneo. No es necesario recordar a Diego Rivera o a David Alfaro Siqueiros, entre otros muchos ejemplos que vendrían al caso. 
Más interesante es, creo, considerar la actividad filológica y gramatical de la RAE en aquellos tiempos y observar cómo surge esta misma tendencia unificadora y de homogenización de lo diverso en estos años. Hagámoslo en dos de los tres pilares fundamentales de la gramática, entendida como un objeto cultural: la gramática y el diccionario.

Podemos empezar viendo de qué manera se recogía en los diccionarios académicos de esta época un término cultural que había cobrado una gran importancia ya en el siglo XIX en la historia de las ideas de Latinoamérica: indigenismo. Este término, empleado para caracterizar un planteamiento político y cultural reivindicativo relacionado con la apreciación positiva de los pueblos nativos americanos y de sus valores, no se encuentra recogido en el $D R A E$ en las ediciones anteriores a 1927. Cuando por fin aparece, se recoge de la siguiente manera:

Indigenismo. m. Condición de indígena.

El término se trata como un simple concepto vicario que se limita a reflejar, como sustantivo, el mismo significado que tiene la palabra indígena. E indígena es definido de la siguiente manera:

Indígena. adj. Originario del país del que se trata.

Por lo tanto, el término indigenismo se entiende aquí, sencillamente, como la condición de ser oriundo del propio país. El término está despojado de todo significado cultural o político; no refleja propiedad específica alguna de los habitantes de ninguna tierra en particular. Indigenismo se aplica de igual manera a los habitantes de Zambia, cuando se habla de dicha nación, y, en situaciones comparables, a los de Mónaco, España o Canadá. Esta misma definición se mantiene en la edición de 1950 del DRAE.

No nos parece casual que esta dirección, en la que el término se despoja de toda propiedad sustantiva y de cualquier denotación de movimiento cultural, sea la que adopte en ese momento la institución que define el uso correcto del léxico español. Más importante que lo que esta definición tiene es lo que le falta: toda referencia a las propiedades distintivas que, sin marchamo oficial, estaba adquiriendo en aquellos tiempos ya el término indigenismo. La correlación con la propuesta de Vasconcelos acerca del mestizaje nos parece notable; de la misma forma que este autor entiendes el mestizaje como una homogenización de las diferencias raciales en una unidad universal, en la que no podía haber distinciones de comportamiento ni propiedades idiosincrásicas específicas, indigenismo se define aquí de la forma más general y abstracta posible, tal que pueda aplicarse a todos los casos: lo que pertenece a una nación -la que seacuando se está hablando de ella.

Conviene hacer notar, antes de seguir adelante, que recientemente ha habido debates en los que se culpa a la RAE de una actitud sexista o discriminatoria, reflejada en el diccionario, ante ciertas ideologías, razas o tendencias. En respuesta, la Academia se ha defendido de estas acusaciones notando que, como lexicógrafos, su deber es el de reflejar el uso que se le da a una palabra en la sociedad, sin prejuzgar si este uso es 
moralmente condenable o no ( $c f r$. las declaraciones del académico José Antonio Pascual en de Cózar, 2006). Así se explica, por ejemplo, que la quinta acepción del término gallego en el DRAE (edición de 2001) dé la equivalencia 'tonto'. No es la RAE la que califica a los gallegos de tontos; es cierta parte de la sociedad la que iguala estos dos términos. La RAE se limita a recoger esta realidad, que a algunos resultará insultante, pero no queda otro remedio si se quiere dar cuenta del uso real del término.

Sin embargo, no es esto lo que sucedía con la definición de indigenismo en 1927 y 1950. Queda constancia en varios textos, sobre todo peruanos, de que ya en aquellos años el término había tomado el significado que se le da, como movimiento cultural, en la actualidad. Así, escribe el autor peruano Felipe Sassone en 1939:

¡12 de octubre! Día de la Raza. ¿De qué raza? ¡Ah, no sé! [...]. La latinidad de la América morena sólo puede estar en el entendimiento y en el corazón: está en el entendimiento, cuando comprende que no puede ser indigenista, porque el indigenismo no tiene ya sentido histórico, puesto que carece de eficacia civilizadora ( «Las mujeres de nuestra América»; Horizonte, octubre de 1939; apud CORDE).

Es claro que en este texto, indigenismo no tiene el sentido que le da el $D R A E$ entre 1927 y 1950. No tendría sentido si fuera así, ya que el autor defendería entonces que América Latina debería ser cualquier cosa menos América Latina. Demos un último ejemplo, este del historiador peruano Daniel Valcárcel, hablando de Túpac Amaru en 1947:

El impacto ideológico que recibe, modifica y perfecciona sus puntos de vista. A la motivación indigenista y reivindicatoria del incanato, a la simple revancha de casta, seguirá un sentido de integración peruanista avasallador. Esta visión aglutinante de Túpac Amaru procede, en lo esencial, de la tradición imperial incaica (La rebelión de Túpac Amaru, p. 234; apud CORDE).

En este caso es todavía más obvio que el término no se emplea ni siquiera para designar a la identidad regional (en este caso peruana), sino para referirse a una noción racial que se sobrepone a las naciones.

En justicia, hemos de decir que el uso abstracto y casi matemático que el $D R A E$ da a indigenismo está documentado en esos años, precisamente en un autor español, José Ortega y Gasset. Obsérvese cómo, más allá de posibles ambigüedades, el término es igualado a la voz autoctonía, que se limita -hasta donde se nos alcanza- a reflejar la adscripción territorial de los nativos de un lugar sin hacer distinciones raciales.

Se trata, pues, de dos propensiones intelectuales de la que una se complace en subrayar la emigración o movimiento de las formas y la otra su autoctonía o indigenismo, su estática (Artículos entre 1917 y 1933, p. 249; apud CORDE).

Este planteamiento, en el que se ignoran aspectos cruciales de la realidad americana, no se altera cuando observamos el tratamiento de los fenómenos sintácticos. Si nos centramos en el voseo, que posiblemente sea el fenómeno que con mayor 
claridad se identifica como distintivo del español de América (aunque, por supuesto, ni sea común a todas ellas ni funcione igual en todos los casos), comprobamos que no aparece mencionado en ninguna edición del $D R A E$ anterior a 1957 ni en la Gramática de 1920 (o en la de 1931, que es en lo fundamental una reedición de aquella). En esta ausencia cabe mencionar varios factores. Naturalmente, uno de ellos -no el menor- es el hecho de que las autoridades lingüísticas de las propias naciones voseantes hubieran estigmatizado este uso; recuérdese que Bello lo había rechazado en su Gramática y que la Academia Argentina había maniobrado activamente a favor de la promoción del tuteo. No es raro que en una gramática que se consideraba eminentemente normativa este fenómeno no fuera discutido. No obstante, nos podemos preguntar cómo se había llegado a esta actitud negativa con respecto al voseo, y por qué no habían cambiado las cosas en unos años en los que el poder cultural y económico de España era, comparativamente, ya menor que el de muchas naciones americanas. No parece que sea ajena a esto la actitud cultural oficialista, representada por Vasconcelos. Si el objetivo de la nueva sociedad para abrir paso a una era renovada para la humanidad es neutralizar las diferencias entre las distintas razas y alcanzar un ser humano unificado, tiene todo el sentido que las diferencias lingüísticas se deban sacrificar. Naturalmente la RAE, que en esos momentos trabaja casi exclusivamente desde Madrid y sin mirar a América, resuelva la unificación a su favor, ignorando los rasgos diferenciales americanos. No se podía incluir en la misma gramática el tuteo y el voseo; como había que unificar, la que se escoge es aquella característica del español europeo -y más aún, de la norma central de la Península-, en virtud de los principios clásicos que suponen que, por ser antecedente histórico, una variedad es superior a otra.

3. UNA INDEPENDENCIA CULTURAL (Y LINGÜÍSTICA) A TRAVÉS DE LAS ALIANZAS: EL PANHISPANISMO

Hacia los años 50, las cosas han cambiado enormemente, sobre todo en la cultura promovida oficialmente por ciertos movimientos políticos de Latinoamérica. En este contexto destaca especialmente la figura del presidente mexicano Miguel Alemán, que fue propuesto dos veces al Nobel de la Paz por sus esfuerzos en fomentar el entendimiento entre las naciones americanas, lo que se conoció como panhispanismo. Este concepto, que tiene sus raíces en el anhelo unificador de Bolívar, es en el siglo XX una noción programática que se refleja en el fomento de cambios en la cultura y en la política. Veremos que la actividad lingüística no quedará al margen de esta idea.

La idea es relativamente simple. Debido a la Guerra Civil y a la posterior dictadura, la influencia de España en el exterior se encuentra muy mermada; España no entraría en la ONU hasta 1959, y era considerada en un sentido muy claro un país con un gobierno fascista. Culturalmente, quizá es justo decir, también, que España había sufrido un retroceso cultural considerable. Numerosos intelectuales no afectos al régimen político de España habían tenido que salir del país; muchos, como Luis Buñuel, se habían ido precisamente a México, donde retomaron su producción cultural de vanguardia (en el caso de Buñuel, esto sucedió precisamente a partir de 1950, cuando 
dirigió Los olvidados en terreno mexicano y con actores mexicanos). La cuestión era que al mismo tiempo que España se iba estancando, Latinoamérica tenía cada vez mayores oportunidades de desarrollo: podría convertirse en una alternativa al poder anglosajón tanto en la economía como en la política y en la cultura si conseguía hablar con una voz unificada. Miguel Alemán es muy consciente de esto: promueve el desarrollo económico independiente de México, por ejemplo en forma de la industria petrolífera, y hace lo posible para que, de forma más crucial, las naciones de habla hispana en América formen una especie de frente común y hablen unánimemente en una variedad de asuntos internacionales.

Esta es la base del panhispanismo como movimiento cultural. La creación de una sola voz hispana implica aceptar al mismo tiempo lo que une a las naciones latinoamericanas y lo que las diferencia, buscando una forma de convivencia por encima de sus singularidades. La consecuencia inescapable de esto es que España ya no puede llevar una voz de líder dentro de esa orquesta; tampoco parecía posible, dada la situación en la que se encontraba en esas décadas.

Esto se refleja también en la actitud cultural hacia la lengua. Esta unidad panhispánica se alcanza a través de la lengua común, que es el español y no cada una de las lenguas indígenas que se hablaban en las distintas regiones. Bajo el gobierno de Alemán, se hacen esfuerzos notables para fomentar la alfabetización del pueblo. Como saben quienes estudian la política lingüística, fomentar la alfabetización de grandes poblaciones implica necesariamente promover la lengua considerada de cultura y dejar de lado otras lenguas que puedan convivir en el mismo territorio; esto equivale, en nuestro caso, a promover el español frente a las lenguas amerindias.

Pero esta lengua española ya no es la que se había considerado en los años $30 \mathrm{y}$ antes, cuando se esperaba que el patrón correcto fuera el español de cierta parte de España y las demás variedades eran mejores o peores en tanto que se asemejaran o diferenciaran de este estándar. En el año 1951, por iniciativa de la Academia Mexicana de la Lengua y promovido por el propio presidente Miguel Alemán, se organiza el I Congreso de Academias de la Lengua Española. En esta reunión se acuerda la creación de la Asociación de Academias de la Lengua Española, que, a pesar de estar presidida por la de Madrid -que, por motivos políticos internos, no pudo asistir al congreso-, estaba destinada a englobar a todas las demás con el objetivo último de garantizar la coordinación en los trabajos filológicos que surgieran de esta institución y promover la unidad del español.

Unidad, de hecho, parece la palabra clave en este contexto. ¿Qué tipo de unidad es la que se defendía en esos años? Si nos paramos a pensar, bajo este término pueden entrar realidades muy distintas. Una primera opción es igualar unidad a homogenización, y en tal caso estaríamos hablando de cuestiones ideológicas muy próximas a las que defendía Vasconcelos en su obra. La segunda opción sería la de alcanzar una unidad en la que pudieran respetarse los usos específicos de cada variedad del español, sin que necesariamente se jerarquizaran en función de su mayor o menor proximidad con un patrón pretendidamente perfecto. El programa político e ideológico que está detrás de la creación de la Asociación de Academias es, en sintonía con el resto del movimiento cultural y político que estaba promoviendo el presidente Alemán, 
panhispánico en un sentido muy preciso: cubrir el español a través de todas las naciones donde se habla -especialmente las americanas- y unificarlo desde el respeto a cada variedad.

Por seguir yendo de lo general a lo particular, veamos cómo se refleja esto en la práctica. La creación de esta Asociación probablemente no es ajena al hecho de que en los trabajos oficiales de la RAE de después de 1951 fuera imposible ignorar los usos lingüísticos americanos $\mathrm{y}$, por extensión, las ideologías favorables a la identidad diferenciada de ciertos colectivos dentro del mundo hispánico. Por poner un ejemplo claro donde se observa bien el contraste con respecto a los años 20, esta es la definición de indigenismo en el DRAE de 1956.

Indigenismo. m. Estudio, cultivo y exaltación de los caracteres y antigua cultura de ciertos pueblos autóctonos de América, que hoy forman parte de naciones en las que predomina una civilización europea.

En la siguiente edición, de 1970, esta definición se modifica levemente, aunque es mantenida en lo esencial, y se añade esta segunda acepción:

|| 2. Doctrina y partido que propugna reivindicaciones políticas, sociales y económicas para las clases trabajadoras de indios y mestizos en las repúblicas iberoamericanas.

Es obvio que han cambiado muchas cosas. La primera y, consideramos nosotros, fundamental, es que ahora en esta definición se reconoce la especificidad que el término tiene en el mundo hispanohablante. No estamos hablando del nacido en cualquier tierra, sino específicamente 'de ciertos pueblos autóctonos de América'; ya no estamos ante una definición abstracta que valga para cualquier sociedad, lugar y tiempo. Ahora se presupone una identidad determinada. Más allá de esto, la definición de 1956 (y la de 1970, que no cambia esta parte), reconoce explícitamente que las sociedades americanas no son homogéneas y no están unificadas culturalmente: estos caracteres y esta cultura están en el interior de sociedades en las que predomina una cultura europea. Con esta fórmula, la definición se distingue de los ideales de Vasconcelos, donde todos los caracteres se unifican en un modelo ideal, y, además de reconocer esta idiosincrasia, admite que dicha cultura se encuentra en una posición de subordinación ante la cultura europea predominante. La segunda acepción, por su parte, elabora esta última línea y reconoce el carácter político y reinvindicativo que es una consecuencia natural de la subordinación del indio americano tanto cultural como económicamente.

Ante los nuevos cambios que se habían producido en la relación entre la RAE y el resto de Academias, es lógico que conceptos como el indigenismo ya no pudieran ser ignorados. Sin embargo, que estos usos lingüísticos y esta ideología se reconozca no implica que fuera aceptada; antes al contrario, lo que encontramos en muchos casos es casi una reacción españolista contra estos usos, lo cual se manifiesta tanto en la gramática como en la lexicografía de la época. Tal vez no sea un detalle anecdótico que la RAE no estuviera presente en el primer congreso de la Asociación de Academias 
(aunque sí estuvo en la comisión permanente y la razón de la ausencia fue un veto impuesto por el franquismo).

Prosigamos revisando algunas entradas en el diccionario. Leemos esto en el $D R A E$ de 1956, y en los sucesivos hasta 1992, inclusive.

Peseta (d[iminutivo] de peso, moneda). f. Moneda cuyo peso y ley han variado según los tiempos. Es la unidad monetaria en España.

Duro. \|16. m. Moneda de plata que vale cinco pesetas.

Compárense estas definiciones a la definición monetaria de peso, acepción 13, en la edición de 1956. La definición cambia ligeramente en 1970, donde el valor de la moneda se actualiza, pero la estructura de la entrada sigue siendo idéntica en lo fundamental incluso en el DRAE de 1992:

Peso. \|13. Amér. Moneda de plata de mayor tamaño y cuyo valor oscila según los cambios, pero que no llega a las cinco pesetas del duro español.

Tal vez el lector ya haya advertido la diferencia que separa a esta definición de las de peseta y duro. En esta definición se siente la necesidad de restringir el término al español de América, porque no se emplea en este sentido en España. No obstante, en las definiciones anteriores, por mucho que en ese significado solo sean propias de España, no se siente la necesidad de acotar el término. Esta asimetría es muy sugerente. Da a entender que los usos puramente españoles del DRAE no requieren ninguna acotación geográfica porque la variedad neutra es, sin más, el español que se hablaba en Europa. Cuando el $D R A E$ recoge un término que no pertenece a España, se siente la necesidad de añadir algo, marcándolo de alguna forma que permita al lector entender que eso no es el español estándar. Naturalmente, esta asimetría lexicográfica refleja una asimetría ideológica: el español propiamente dicho es el que se habla en España; lo que se habla en América también es español, pero coloreado por idiosincrasias que deben señalarse expresamente. De nada sirve tener en cuenta que el número de hablantes que usaba la palabra duro para designar 'cinco pesetas' era muy inferior a los que usaban peso para designar a su moneda. El español sin colores, neutro y -se podría añadir- correcto es el que viene de España.

La asimetría se refleja en el tratamiento de otros americanismos. Creemos no equivocarnos al afirmar que el término piripi -que significa 'borracho'- solo se emplea en España. Este dato parece confirmarse en búsquedas de corpus tanto históricos como contemporáneos. Este término entra en el $D R A E$ en 1984, donde se define así:

Piripi. adj.fam[iliar]. Borracho.

No hay restricción geográfica alguna, igual que sucedía con peseta y duro. Compárese con la siguiente definición, introducida por primera vez en 1992:

Briago, ga. adj. Méj. Borracho, ebrio. 
Algo parecido sucede con talego, que solo en España se usa como sinónimo de cárcel (por primera vez introducido en esa acepción en 1985):

Talego. || vulg. Cárcel.

Frente a esto, la palabra tambo, que designa a distintos edificios en América (entre ellos, aunque esto no se recoge antes de 2001, la cárcel en México) aparece definida así en 1992:

Tambo (del quechua tampu). m. desus[ado]. Col. Chile, Ecuad. y Perú. Venta, posada, parador. || 2. Argent. Establecimiento ganadero [...] || 3. Argent. Corral donde se ordeña $\|$ 4. Perú. Tienda pequeña.

Creemos que estos ejemplos pueden servir para ilustrar la ideología imperante en estos años: el español, sin más calificativos, es el que se habla en España. Lo demás puede coexistir, pero en una relación de asimetría con respecto a la norma que se habla en la Península (o más bien en parte de ella).

En gramática sucede algo parecido. Podemos comenzar por la definición de voseo en los diccionarios de la época y después nos iremos al tratamiento del mismo fenómeno en el Esbozo de 1973. Este término aparece recogido por primera vez en 1956, pero entonces es definido por referencia a vosear, y este, a vos. Veamos qué dice sobre vos el diccionario ese año:

Vos (del lat. vos). Cualquiera de los casos del pronombre personal de segunda persona en género masculino o femenino y número singular o plural, cuando esta voz se emplea como tratamiento. [...] Este modo de hablar, que tuvo uso general en lo antiguo, empléase hoy todavía para dirigir la palabra a Dios y a los santos o a personas de mucha autoridad, y también en ciertos documentos oficiales, como asimismo en la poesía y la prosa elevada.

El uso de vos que se reconoce en el DRAE de 1956 es el voseo reverencial, que era el único en el que se usaba dicho pronombre en España en aquellos tiempos. No hay referencia alguna al voseo familiar, característico de numerosos países del centro y sur de América. El fenómeno, pues, es tratado prestando atención exclusiva al uso peninsular. Recuérdese, sin embargo, que este fenómeno estaba condenado normativamente en los propios países que lo tenían, lo cual puede ser una causa adicional que contribuya a esta omisión.

La misma definición se emplea en 1970 y en 1984. En 1985, la última parte de la definición se modifica levemente, y comienza a nombrarse a América, aunque, bien es cierto, de forma superficial y algo confusa:

...Este modo de hablar ya solo tiene uso en tono elevado y su empleo está hoy extendido en Iberoamérica. 
Tal como está escrito, parece que en América lo que se emplea es el voseo reverencial, no el familiar. El cambio significativo de 1985 está bajo la definición de vosear:

vosear. tr. Dar a uno el tratamiento de vos o usar este pronombre en lugar de tú, como se hace en algunos países iberoamericanos.

En 1992, el voseo de familiaridad se integra por primera vez en la definición de vos, aunque en ese caso solo se asocie a Argentina:

vos. || 2. Argent. Pronombre personal de segunda persona singular que cumple la función de sujeto, vocativo y término de complemento. Su paradigma verbal difiere según las distintas áreas de empleo.

Hay dos cosas curiosas de esta definición; la primera es que no se aclara nada sobre su uso sociolingüístico, es decir, sobre que se emplea como tratamiento de familiaridad y solidaridad. En la primera acepción, que mantiene en lo esencial lo dicho en 1956, sí se aclara que es un uso reverencial. La segunda cuestión interesante es que, pese a que se adscribe geográficamente a Argentina, en la definición se reconocen distintas áreas donde se vosea, con diferencias flexivas. Estas áreas son las que se distinguen en función de la flexión verbal que acompaña al pronombre vos (por ejemplo, si se usa la forma amás o la forma amái); la definición reconoce de forma implícita que existen otras áreas, además de Argentina, donde se vosea, pero no incluyen estas formas en la adscripción geográfica de la definición.

Asimismo, en todos estos casos parece haber una cierta confusión entre término y concepto. Una cosa son los países en que se utiliza una palabra con cierto significado y otra cosa son los países de los que es propio dicho significado. Por más que el voseo pueda ser característico, como realidad, de Argentina y no de España, el hecho es que en ambos países se puede emplear el término para referirse a este fenómeno: en España para describir un uso foráneo y en Argentina para describir una realidad que se da en el propio país, pero, en definitiva, el término se usa en ambos casos. Esta es una dificultad adicional que se encuentra en la definición lexicográfica de ciertos usos gramaticales: al contrario de lo que sucede con términos como piripi, que son exclusivos de ciertas zonas y por ello deberían ir acompañados de indicaciones geográficas, palabras como voseo se emplean de forma general en las comunidades de gramáticos de uno y otro país para referirse a unos mismos fenómenos. En este segundo caso, la adscripción geográfica hubiera aparecido con mayor propiedad como parte de la definición, ya que la restricción se refiere al concepto y no al uso del término.

Dejando esto, que merecería un artículo en sí mismo, a un margen, podemos proseguir viendo cómo se trata el voseo en el Esbozo, que, como se sabe, fue el intento de editar una nueva gramática que la RAE encargó a los gramáticos Samuel Gili Gaya y Salvador Fernández Ramírez. El libro, publicado en 1973, alude directamente al voseo. Lo hace en cinco ocasiones, y en la forma de tratarlo se advierten ya dos cambios fundamentales. El primero, obvio, es que se dedica algún espacio al tratamiento del 
voseo; el segundo, menos obvio, es que sigue tratándose desde una perspectiva fundamentalmente europeocéntrica, y el texto está nítidamente más preocupado por el origen histórico del fenómeno - que estaría en España- que por el uso americano que se hace de él.

Así, en la sección dedicada a la ortografía ( $§ 1.8)$, se alude al voseo en dos ocasiones (notas 48 y 49). En la primera nota se habla del origen histórico de la caída de - $d$ en las formas de imperativo plural (cantá por cantad, que el Esbozo documenta en San Juan de la Cruz) y se apunta de pasada que los imperativos sin $-d$ final siguen vivos en las zonas americanas de voseo, donde equivalen a la segunda persona singular. En la nota siguiente, la 49, se habla de las reglas de acentuación correspondientes a estas formas y el uso americano se compara a un caso tomado de Juan de Valdés. También se menciona superficialmente el voseo en dos capítulos dedicados a la sintaxis. La nota 2 (§ 3.13.5), en la sección dedicada al imperativo, añade a lo anterior que los imperativos irregulares sal, ven, etc., en las zonas voseantes contienen vocales finales tónicas (salí, vení, etc.). La nota 1 de la sección dedicada a la colocación de los posesivos (§ 3.10.10) vuelve a aludir al voseo, pero esta vez no al uso americano, sino claramente al voseo referencial que usa la forma vuesa (vuesa merced) para referirse a una segunda persona singular. No obstante, es necesario mencionar que esta nota no menciona el voseo, aunque el índice de materias remita a esta sección bajo la entrada correspondiente.

Hay, empero, una sección completa dedicada al voseo, la $\S 2.14 .7$, encuadrada dentro de la discusión de las formas de tratamiento en la sección de morfología. Creemos que resulta ilustrativo considerar como comienza la exposición del fenómeno en el primero de los tres apartados que configuran la sección:

2.14.7. Voseo. -a) Según hemos visto ( $\S 2.14 .3 b$ ), el vos fue desplazado del trato respetuoso por vuestra merced $>$ usted, compitió con el tú como tratamiento de confianza y en España fue desalojado por él. Pero en gran parte de América formó con el tú tradicional un solo paradigma para un solo destinatario [...].

A continuación, la Gramática describe la morfología verbal y pronominal de la variedad de voseo más frecuente - del Río de la Plata-, destaca aquellas formas que no se emplean ya en España, señala algunas diferencias con otras variantes de voseo familiar y lista algunas de las regiones donde se da el fenómeno. Lo interesante es, en nuestra opinión, que en todos los casos el voseo se presenta, fundamentalmente, como un fenómeno que tiene sus raíces en la Península y lo que se destaca es casi exclusivamente cómo usos peninsulares antiguos han sido adoptados en las variantes voseantes y en qué sentido son diferentes del español europeo. Como sucedía en el $D R A E$, parece que la mentalidad es que el español, cuando se nombra sin calificativos, es el español de España, y los demás fenómenos que distinguen otras variedades han de subordinarse a él, y resultan interesantes en la medida que ilustran la historia de esa variedad de lengua o establecen contrastes con la variedad estándar. A cambio, es cierto que estos fenómenos de variación comienzan a tratarse y que, aunque de manera sucinta, hay cierto interés por las variedades americanas. Nótese que, de cinco 
menciones, solo una de ellas habla exclusivamente del voseo reverencial y las otras cuatro se concentran sobre todo en el voseo de familiaridad americano.

No podemos olvidar que el Esbozo de 1973 es una gramática que viene de España, comisionada por la Real Academia Española (véase la advertencia inicial: $L a$ Real Academia Española [no la Asociación de Academias] saca a la luz este Esbozo...) y escrita por dos autores nacidos en España. Don Samuel Gili Gaya había nacido en Lérida y don Salvador Fernández Ramírez, en Madrid; ambos desempeñaron su magisterio en Madrid. Esta gramática es, por lo tanto, fundamentalmente española, recoge los usos españoles y, en lo normativo, sigue considerando estándar el uso del español peninsular central, el que no tiene laísmo pero sí leísmo de persona (cfr. 3.10.5c).

En conclusión, en los años que van desde 1951 hasta 1992, la actividad lingüística y filológica de la RAE queda influida por el concepto de panhispanismo, pero no de la forma que Alemán hubiera deseado: aunque se reconoce la existencia de fenómenos de variación en América y, frente a la etapa anterior, se hace un esfuerzo por conocerlos, estos fenómenos no se integran en el sistema y se hace una distinción clara entre lo que es fundamental y estándar -la variante europea- y lo que es accesorio y subordinado a esta-las variantes americanas-.

\section{ESPAÑA SE ABRE A LATINOAMÉRICA}

Cae la dictadura en España y los gobiernos democráticos tratan de restablecer relaciones diplomáticas y económicas con las naciones latinoamericanas. El movimiento es particularmente reconocible a partir de 1982, con la llegada del gobierno socialista de Felipe González: se recuperan las relaciones diplomáticas con Cuba -frenadas por el anticomunismo de Franco-, se suceden los viajes oficiales y acuerdos de cooperación económica con Chile, Argentina y otros países que, en la época, trataban de establecer o consolidar la democracia, y se firman acuerdos comerciales entre esos países y empresas (entonces) nacionales españolas como Repsol, Telefónica o Endesa. En 1985 se crea la SECIPI, que, como su propio nombre manifiesta (Secretaría de Estado para la cooperación internacional y para Iberoamérica), está centrada muy especialmente en los países americanos; poco después, en 1988, dependiendo de esta secretaría de estado, se crea la Agencia Española de Cooperación Internacional, en la práctica también muy dedicada a Latinoamérica. Con la vista puesta en el Quinto Centenario, tiene lugar en 1991 la primera Cumbre Iberoamericana, en la que solo se aceptan países que tengan el español (o el portugués) como lengua mayoritaria, y cuyo objetivo prioritario es facilitar la cooperación y el desarrollo.

Obviamente, la motivación de muchas de estas iniciativas es económica: España se da cuenta de que para su propio desarrollo le resulta conveniente establecer medios de comunicación directos, y en pie de igualdad, con las naciones americanas. Sin embargo, no es ajeno a esto un movimiento general de aprecio cultural, dentro de España, por lo latinoamericano. No es una mera anécdota, por ejemplo, que tres años después de fundarse, los premios de la Academia de Cine española (los Goya) tuvieran 
ya una categoría designada para el cine latinoamericano (Mejor película extranjera de habla hispana), que continúa hasta la actualidad, y ya ha dejado de ser noticia que un actor, un director o una película latinoamericana sea candidata en las demás categorías (la más reciente, la película argentina El secreto de sus ojos, en 2009). Todo este proceso de igualación e integración desde la diferencia se refleja, fundamentalmente, en que la actividad lingüística de la RAE comienza a aplicar los principios fundamentales del panhispanismo en su metodología.

Para muestra, un botón: en la vigésima segunda edición del $D R A E$, esta es la entrada de duro.

Duro. $\|$ 15. m. Esp., moneda de cinco pesetas.

Ahora se marca la adscripción geográfica, dejando claro que este término solo se usa en España. No se extiende esta decisión a todos los casos (así, en talego y piripi no se ha añadido este diacrítico), pero sí aparece usado en numerosos casos. El cambio muestra que la RAE da pasos hacia la consideración en pie de igualdad de todas las variedades del español, sin suponer que el español no marcado es el de España. Ahora, se reconoce que este uso de duro es tan marcado geográficamente como briago y otros términos restringidos a ciertas zonas; ambos no pertenecen al español general y debe mencionarse expresamente que son propios de dialectos específicos.

El $D R A E$ de 2001 es la primera obra editada por la Real Academia Española en colaboración con la Asociación de Academias, aunque la RAE aún figure como única autora en la portada y lomo. La propia RAE deja claras las razones de este cambio en su página web:

\section{La política lingüística panhispánica}

En los últimos años, la Real Academia Española y las veintiuna Academias de América y Filipinas que con ella integran la Asociación de Academias de la Lengua Española vienen desarrollando una política lingüística que implica la colaboración de todas ellas, en pie de igualdad y como ejercicio de una responsabilidad común, en las obras que sustentan y deben expresar la unidad de nuestro idioma en su rica variedad: el Diccionario, la Gramática y la Ortografía.

La palabra clave es aquí panhispanismo, e implica una colaboración en pie de igualdad entre todas las Academias de la Lengua Española. Esta colaboración científica y política se refleja necesariamente en una ideología lingüística que busca preservar la diversidad dentro de la unidad del idioma. El lema es ahora «Unidad en la diversidad»:

Las Academias desempeñan [la fijación de la norma del idioma] desde la conciencia de que la norma del español no tiene un eje único, el de su realización española, sino que su carácter es policéntrico. Se consideran, pues, plenamente legítimos los diferentes usos de las regiones lingüísticas, con la única condición de que estén generalizados entre los hablantes cultos de su área y no supongan una ruptura del sistema en su conjunto, esto es, que ponga en peligro su unidad. 
Esta nueva metodología, como hemos visto, no se había aplicado anteriormente. La actitud previa, que implicaba considerar el español como una entidad monolítica de la que se habían alejado algunas zonas geográficamente remotas, es sustituida ahora por un planteamiento policéntrico en el que se reconocen varias normas igualmente aceptables que se integran en un solo idioma. La tensión que surge de aquí es la de cómo conjugar la diversidad con la unidad, y la RAE propone lo siguiente: es aceptable cualquier uso culto siempre y cuando no afecte al conjunto del sistema gramatical, léxico y ortográfico del español. Es posible discutir por extenso qué cambios rompen el sistema y cuáles son solo variaciones sobre él, pero ahora la metodología está clara: las Academias deben, colectivamente, consensuar unas normas, sin que el voto de ninguna de ellas valga más que el de las demás, y será el conjunto de las Academias el que decidirá si un uso particular rompe la unidad o no lo hace. No cabe ya la posibilidad de imponer tácita o expresamente un uso español, condenando las variantes americanas correspondientes ( $c f r$., sin embargo, del Valle, 2005, 2007 para una visión más crítica de esta metodología y de sus intenciones últimas):

En una tarea de intercambio permanente, las veintidós Academias de la Lengua Española articulan un consenso que fija la norma común para todos los hispanohablantes en cuestiones de léxico, de gramática o de ortografía, armonizando la unidad del idioma con la fecunda diversidad en que se realiza.

Cronológicamente, la siguiente obra en la que se aplica esta colaboración panhispánica tanto en su metodología como en su teoría es el Diccionario Panhispánico de Dudas (2005). Esta era la empresa en la que se ponía a prueba con mayor rigor la metodología de conjugar diversidad con unidad: la construcción de la norma culta. Considérese, como ilustración de la nueva ideología, la entrada correspondiente al voseo en esta obra. Lo primero que llama la atención es la extensión que se dedica al fenómeno: tres páginas a doble columna y dos páginas más con tablas de conjugación. En segundo lugar, es destacable que se diferencien cuidadosamente el voseo reverencial del familiar, y que se dedique mucho más al segundo que al primero. El tercer cambio llamativo es que se dedica un largo epígrafe a la aceptación del voseo en la norma culta (§ 2.4, p. 674) y todavía más, la forma en que se trata:

Las diversas modalidades voseantes gozan hoy de diferente estimación.

2.4.1. En líneas generales, la norma culta prefiere el tuteo en el Perú, Bolivia, América ecuatorial -excepción hecha de Zulia y la franja occidental colombiana-, Panamá, México y las Antillas. En estas zonas el voseo carece de prestigio y es indicador de escasa formación.

2.4.2. Salvo en Panamá [...], el voseo de tipo Rioplatense goza de total aceptación en la norma culta centroamericana, pero como fenómeno propio del habla familiar [...].

2.4.3. En los países del Río de la Plata, el voseo goza de total aceptación en la norma culta, tanto en la lengua escrita como en la oral, y ha sido explícitamente reconocido como legítimo por la Academia Argentina de la Lengua [...]. 
Estos fragmentos ilustran la nueva metodología: se establecen distinciones regionales y para cada una de ellas se da una norma social diferente. Esto es el policentrismo: reconocer variedades y aceptar el juicio que cada una de ellas merece para sus propios hablantes (al menos, los considerados cultos), sin juzgarlas desde fuera en virtud de un patrón exclusivo que coincida con una de las variantes.

Esta misma metodología -o incluso una versión más explícita de ella- se ha aplicado también en la elaboración de la Nueva Gramática de la Lengua Española (2009). Esta obra está llena de referencias dialectales que especifican con gran detalle la extensión geográfica de un fenómeno o de una expresión. En el caso del voseo, la NGRAE dedica extensas secciones a su uso pragmático $(\S 16.7)$ y a sus propiedades flexivas (§ 4.7). Es cierto que en la versión final de la obra se deslizaron algunos errores en la tabla, particularmente en el caso de Costa Rica ( $c f r$. Quesada Pacheco 2010), pero la preocupación que ha causado este error expone de forma clara cuál es la nueva actitud: ahora ya se espera que la gramática académica cubra en detalle y con precisión todos los usos americanos, y la RAE -en tanto que coordinadora de la obra- acepta su responsabilidad en garantizar que esto sea así en la versión final. Está claro que, en otros tiempos, ni las expectativas ni las responsabilidades se habrían distribuido así.

\section{CONCLUSIONES}

Cerremos este trabajo con una breve recapitulación. Hemos tratado de mostrar que la historia de las ideas y la gramática no son compartimentos estancos; la gramática queda influida por las ideologías, lo que se manifiesta en detalles sutiles de la práctica gramatical -como los diacríticos en un diccionario-, en la elección de los temas que uno decide tratar y en a la perspectiva que adopta dicho tratamiento. En esta brevísima presentación hemos intentado mostrar cómo distintos conceptos políticos e ideológicos acerca de la identidad americana y su relación con otras culturas han ido reflejándose en el tratamiento lexicográfico y gramatical de aspectos de la realidad lingüística americana. Esperamos haber mostrado que un análisis de este tipo puede arrojar más luz tanto sobre cuestiones culturales como sobre las prácticas lingüísticas que, aun presentándose como neutrales, esconden prejuicios ideológicos en su interior.

\section{REFERENCIAS BIBLIOGRÁFICAS}

De CózAR, Ángel (2006): «El dicionario impertinente», El País, 25 de junio de 2006.

Del VALle, José (2007): «Embracing diversity for the sake of unity: linguistic hegemony and the pursuit of total Spanish», en Heller, Monica y Alexandre Duchêne, eds., Discourses of endangerment: interest and ideology in the defense of languages, Londres, Continuum International, 242-67.

Del VALLE, José (2005): «La lengua, patria común: política lingüística, política exterior y post-nacionalismo hispánico», en Wright, Roger y Peter Ricketts, eds., Studies 
on Ibero-Romance Linguistics Dedicated to Ralph Penny, Newark (Delaware), Juan de la Cuesta Monographs (Estudios Lingüísticos, vol. 7, 391-416).

HiLl, Matthew J. K. (2009): The indigenismo of Emilio «El indio» Fernández: Myth, Mestizaje and Modern Mexico, tesis doctoral inédita, Provo (Utah), Brigham Young University.

MANTILla Pineda, Beningno (1968): «Sociología de la novela indigenista», Universidad de Antioquía, vol. 170, 955-979.

PÉREZ DE COLOSÍA, María Isabel (1976): «El indigenismo y las novelas de Ciro Alegría», Anales de literatura hispanoamericana, vol. 5, 165-194.

QuesadA PACHECO, Miguel Ángel (2010): «El voseo costarricense en la Nueva Gramática». La nación, 13 de junio de 2010.

Real ACAdemia Española (1925): Diccionario de la lengua española. Décima quinta edición. Madrid: Calpe.

Real Academia Española (1936): Diccionario de la lengua española. Décima sexta edición. Madrid: Espasa-Calpe.

Real ACADEMia EsPañola (1947): Diccionario de la lengua española. Décimoséptima edición. Madrid: Espasa-Calpe.

Real Academia Española (1956): Diccionario de la lengua española. Décimoctava edición. Madrid: Espasa-Calpe.

REAl ACAdEMia Española (1970): Diccionario de la lengua española. Décimonovena edición. Madrid: Espasa-Calpe.

Real ACADEMia Española (): Diccionario de la lengua española. Vigésima edición. Madrid: Espasa-Calpe, 1984.

Real ACAdEMia EsPañola (1992): Diccionario de la lengua española. Vigésima primera edición. Madrid: Espasa-Calpe.

Real ACAdemia Española (1927): Diccionario manual e ilustrado de la lengua española. Madrid: Espasa-Calpe.

Real ACAdemia EsPañola (1950): Diccionario manual e ilustrado de la lengua española. Segunda edición. Madrid: Espasa-Calpe.

Real ACADEMia Española (1985): Diccionario manual e ilustrado de la lengua española. Tercera edición revisada. Tomo VI. Sal-Zuzón. Madrid: Espasa-Calpe.

REAl ACADEMia EsPañola (1973): Esbozo de una nueva gramática de la lengua española. Madrid: Espasa.

Real ACAdemia EsPañola (1920): Gramática de la lengua española. Madrid: Calpe.

REAl ACADEMIa EsPaÑola (1931): Gramática de la lengua española. Madrid: Espasa.

REAl ACADEMia EsPañola y Asociación DE ACADEMIAS DE LA LENGUA ESPAÑOla (2009): Nueva gramática de la lengua española. Madrid: Espasa.

Real ACAdEMia EsPañola y Asociación de ACAdEMias de la Lengua EsPañola (2001): Diccionario de la lengua española. Vigésima segunda edición. Madrid: Espasa.

Real ACADEmia Española y Asociación de ACAdemias de la Lengua Española (2005): Diccionario Panhispánico de dudas. Madrid: Santillana.

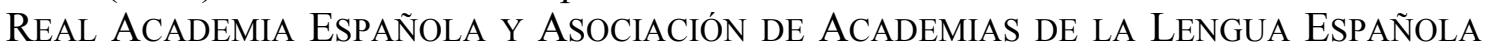
(2010): Ortografía de la lengua española. Madrid: Espasa. 
TIERNEY, Dolores (2007): Emilio Fernández: Pictures in the Margins. Spanish and Latin American Filmmakers, Manchester, Manchester University Press.

VAsconcelos, José de (1925): La raza cósmica, Madrid, Agencia Mundial de Librería. 